ted, for the art of drawing is of inestimable service to the anatomist and pathologist.

In this short letter upon the College at Alfort, I have not pretended to broach any of the numerous questions which at present agitate the veterinary world. I have, perhaps, written at once too little and too much, but should this superficial review fail to satisfy your interest and curiosity concerning the science, I may attempt, upon some future occasion, to do higher justice to so important a subject.

The veterinary colleges of France are the most perfect that exist; let us take them for our model, and seek to emancipate in the new world a noble science, that still struggles for independence and justice in the land of our fathers.

Alfort, June 8th, 1847. Your friend,

EdWARd Brooks, Jr.

\title{
ON THAT KIND OF APHTHA PECULIAR TO FEMALES, PARTICU. LARLY THOSE IN THE PUERPERAL STATE.
}

[Communicated for the Boston Meil. and Burg. Journul.]

SEveral writers have published articles in the Journals on aphtha lactea, nursing sore mouth, puerperal anæmia, \&c. ; but standard authors are silent on this distinct kind of aphtha, so far as our acquaintance with medical literature permits us to judge, which proves to us that the complaint is of recent date, or that it is not very fiequent in its appearance. I am inclined to the opinion that it is of modern origin, else it would have been distinctly noticed by those accurate writers who have gone before us; and my own experience teaches me that it is on the increase, for I have seen more cases of the complaint during the last year, than 1 did in four times that period previously.

Canker is a popular term in New England for a sore mouth; hence the name "nursing canker," which means the same thing as the technical terins aphtha lactea, puerperal anæmin, \&c.

I object to these terms, because they are not truly expressive of the disease, for I am sure that females who are in the virgin state are obnoxious to it, but í willingly admit that they are not so liable as those who are pregnant, or in a condition dependent on pregnancy. But as the terms tend to error, by confining the disease altogether to those who nurse, or are in the condition of child-bearing, they had better be laid aside and some more eligible name secured instead of them.

In this disorder, as in chlorosis, there is great depravity of the blood, which fluid I suppose in both diseases to be wanting in its essential elements, the red globules and the fibrin. As in chlorosis, there is more or less functional disturbance. But the mucous membrane of the alimentary canal is in a peculiar state of inflammation; the mouth and fauces are covered with white vesicles, which after a time scale off, leaving the membrane red and glairy. This same condition exists sometimes on the membrane of the vagina and rectum, and without doubt the 
same obtains in the stomach and intestines. This constitutes the formidable disease under consideration.

All inordinate secretions cause debility; and the secretion of the mammary glands, if too abundant, may be a cause of nursing canker. Women at times are obliged to wean their infants, which is more effectual in certain cases than medicine. Amenorrhca may be productive of the thrush, and all the causes enumerated in the articlo on chlorosis in a former No. of this Journal, are also causes of the kind of aphtha peculiar to females. [Vill. Journal, vol. xxxvii., p. 55.]

The leading symptoms are anæmic pallor, cachectic œdema, gastralgia, diarrhœa, neuralgic pains, hot and diy skin, frequent pulse, lassitude, morbid or impoverished appetite, emaciation, vomiting, indigestion, \&c. There is inflammation of the buccal and lingual mucous membranes. The parts are found red or of a pink color, the tongue white and glossy, its edges and other portions covered with white specks, or dry and inflamed. So with the fauces. That this is the condition of the intestinal tube, is evident from the diarrhœe, the irritability of the stomach, and the tenderness on pressure over those regions.

If the complaint is suffered to run on unchecked for a great length of time, there is danger of its undermining the constitution to such a degree that the mischief may become irreparable; but before it has made such deep inroads, it generally yields to the resources of our art, as readily as could be expected when we take into consideration the nature of the disease.

The remedial agents to be employed are of two classes, tonics and irritants ; but they should not be had recourse to until all functional derangements are restored.

Of the first class, the ferruginous preparations, quinia, cinchona, nitrat. argenti, and the vegetable bitters, are all useful; but iron and quinine are the best.

Of the second class (those remedies that I denominate irritants) I prefer cantharides, capsicum, calomel, creosote, and the nitrate of silver, which last is an irritant tonic. The modus operandi of the last medicines is explained upon the same principle as that which accounts for the good effects of the nitrat. argent. in chronic conjunctivitis, which is familiar to all medical men. In aphtha the inflammation is not acute, but is of such a character that we cannot cure it until we get up a new action in the affected parts; then by instituting a tonic and soothing course, the integrity of the system will be restored and health established.

After correcting functional disturbances, if diarrhœa be present, I give a pill of nit. argent. three times a-day, and a Dover's powder at bed time; directing, at the same time, gum water for drink, and bread and water for diet. Under this treatment the looseness of the bowels soon disappears, especially if a few leeches or tartar emetic ointment are applied to the belly, a thing very often necessary to do on the principle of counter-irritation, or revulsion, if the old term is more applicable.

If there is no diarrhoea, I give the tincture of cantharides till the proper impression is made upon the diseased membrane. After this, in both 
instances, I resort to tonics. I have administered tonics and irritants conjointly :-R. Tinc. ferri chlo., tinc. cantharid., ää $\bar{\jmath}$ j. M. Dose, from twenty drops to two teaspoonfuls three times a-day ; or the tinc. cantharid. nay be given with Griffith's mixture, the last-named medicine being one of great value in the complaint. The mistura creosoti, or creosote mixed with mucilago-acaci in the proportions of sixteen drops of the former and an ounce of the latter, I have used with success in two cases. The dose of the last is a teaspoonful three times a-day in sweetened water. Quinia, as a 'tonic, is inferior to iron, but may be resorted to in some instances, especially where the latter disagrees with the patient's constitution; so with the vegetable bitters, \&ec. But no two remedies have done so well in my hands as steel and cantharides.

Mucilages of gum Arabic, tragacanth and flaxseed tea, may be usefully employed.

Sedatives, when there is pain and restlessness, must be resorted to. Opium, morphine and hyoscyamus, are as good as any medicines of their kind.

Gargles are not of much use (perhaps hurtful) till the constitutional remedies are instituted and found to be doing good. Borax, alum, mineral acids, tincture of myrrh, \&c., form excellent gargles, to which we might add sul. zinci, acid. tannic., \&c. An ounce of spts. nit. dul. saturated with tannic acid, forms one of the best local applications. This may be applied to the mouth two or three times a-day, or even oftener, by means of a camel-hair pencil, with great relief to the patient; or the nit. argent. or sul. cupri. may be employed in strong solution or in substance. I have used a solution of the acetate of lead as a wash, and combined with opium I have found it a useful internal remedy. "Ablutions with warm water, whenever the patient's strength will admit of it, should precede the use of gargles." When convalescence is established, a more generous diet is advisable, and riding, the shower bath, shampooing and proper exercise should be used.

I am aware that puerperal women are the most frequent subjects of aphtha, and $I$ account for it on the ground that nursing has a tendency to debilitate a constitution already infirm or predisposed to disease ; but I am equally certain that others are its subjects, and in proof will give the outlines of a case that lately occurred in my practice.

CASE I.-Miss I., aged 18. She had not menstiuated regularly for the last six months previous to my seeing her, and for the last two months she had not been "unwell." Appetite poor, pulse frequent, diarrhœa profuse, the affection of the mouth severe, countenance pale, and complains of great prostration. The tongue was of a polished pink color, the buccal membrane lined with white specks, a burning sensation at the rectum, and a scalding sensation was felt in passing urine. The stools were clay-colored, and there was other evidence of deranged liver.

At first I gave her a powder of small quantities of capsicum, acetate of lead and Dover's powder every three hours. At bed-time she took half a grain of calomol and an eighth of a grain of morphia. After six days she took two teaspoonsful of castor oil. Then I gave her the 
iron and cantharides for another week. I then gave her the myrrh mixture, which she continued nearly a fortnight, and she is now enjoyingr good health.

Calomel was employed here both as an alterative and an irritant. Prof. Beck says that this medicine, given in large doses, acts " as a powerful sedative" ; in small doses, he says it acts " as a stimulant, or rather irritant."-(Vid. New York Journal of Medicine, March No. for 1847, page 177.)

CASE II.-Mrs. C., aged abont 30, has borne three children; general health feeble. Hor mouth always some sore while nursing, but with her last child there was more of it than usual. She grew worse, and at length I was requested to visit her. I found her much emaciated, pulse sharp and frequent, oedematous condition of the lower extremities, some looseness of the bowels. She complained of indigestion, of wandering pains of a neuralgic character, of prurigo about the labia pudendi, and there was tenderness when pressure was made over the epigastrium.

She took pills of nit. argent. and applied the tartal emetic ointment to those parts where soreness was found on pressure. The ungt. hydrarg. ammo. was applied to the seat of the prurigo. In four days I discontinued the pills, and gave her flies and iron. She improved rapidly.

The worst case of aphtha that has ever fallen under my notice occurred last winter. The patient is now in good health. The usual remedies were employed, with leeches to the abdomen. In this case I think I obtained signal advantage (the diarrhœa was profuse) from pills of the acetate of lead and opium. The sweet spirits of nitre, saturated with tannic acid, proved an exceedingly useful local remedy.

About four years ago I attended a young lady who had aphtha. She had never menstrated, and was chlorotic. She took the following :-R. tinc. sanguinari., tinc. fer. chlorid., tinc. cantharid., āā $z j$. M. Dose, a teaspoonful three times a-day. Detergent gargles were employed, and she soon recovered.

I have investigated this subject with caution, and here give it as my opinion that not only are women and virgins obnoxious to the disease, but so are men. I admit I have never seen any well-marked cases in the male sex, but my knowledge of the pathology of the disorder does not permit ine to doubt that they may and do occur. Will some one tell me why they cannot? Men have chlorosis, why not chlorotic aphtha? We know that men are not so liable to some particular diseases as women, and vice versa ; but this does not controvert the assertion just made. August 27, 1847.

Claudian.

\section{PSEUDO-EPILEPTIC AFFECTION ARISING FROM DECAYED TEE'TH.}

To tho घditor of the Boston Medioal and Surgloal Journal.

Sir,-The following singular and interesting case presented itself to my notice a short time since; and in itself offers abundant evidence (if any were required) of the necessity, not, as is contended, that a medical 